back to the whole group before Dr Ken Day summed up the experience of the conference. He concluded that all the best conferences throw up more questions than are answered. For example, is it ever relevant to teach mental handicap without involving the multidisciplinary team? Are video films an effective alternative to meeting people with mental handicap face to face? Should there be a separate core syllabus for mental handicap or a coordinated syllabus on chronic disability with mental handicap as just one of several disabilities? The final session had certainly highlighted a need for medical schools to define educational aims and objectives more clearly.

A detailed account of each of the research presentations is being prepared by the respective authors for publication elsewhere.
REFERENCES

${ }^{1}$ Holt, K. S. \& HuntLey, R. M. (1973) Mental subnormality: medical training in the United Kingdom. British Journal of Medical Education, 7, 197-202.

${ }_{2}^{2}$ PILKington, T. L. (1977) Teaching medical students about mental handicap. Developmental Medicine and Child Neurology, 19, 652-658.

${ }^{3}$ Holuins, S. C. (1982) The way we teach the psychiatry of mental handicap to undergraduates. Association of University Teachers of Psychiatry Newsletter, December 1982.

4 _ (1985) What every medical student needs to know about the psychiatry of mental handicap. Association of University Teachers of Psychiatry Newsletter. Summer 1985.

Sheila Hollins, Senior Lecturer

ELSPETH BRADLEY, Senior Lecturer St George's Hospital Medical School, London SWI7

\title{
Woodford-Williams Prize
}

Dr Eluned Woodford-Williams, CBE, was a pioneer of British geriatrics, and in recognition of her services to psychiatry both in that capacity and as Director of the Health Advisory Service, the College elected her a Member and later a Fellow. She was an enthusiastic member of the Section for the Psychiatry of Old Age until her death in 1984 and this Prize derives from the bequest which she made to the College.

A Prize (value $£ 300$ ) is offered every three years commencing in 1988 for research in the prevention of dementia. The research should be within the broad heading of the prevention of dementia. It is noted that the wider aspects of prevention (including primary, secondary and tertiary prevention) give a range of possible topics.

Applicants for the Prize must be Members of, or Associates with, the College*. Research involving collaboration between workers, whether psychiatrists or in other disciplines, may be submitted, but the Prize may be shared between no more than two eligible applicants. In each instance where collaborative research is submitted there should be a clear indication of which parts of the research were undertaken by each worker and a statement to this effect signed by all collaborating workers must be submitted.

Applicants are required to submit a summary of their proposed submission between 200 and 500 words for approval by the Examiners at an early stage to ensure that it falls within the scope of the award.

The research may be presented in the form of an essay or dissertation or as an account of recently published work in the field. Submissions, which may include figures and tables, should be between 10,000 and 30,000 words. A concise curriculum vitae, together with a list of any appropriate publications, should accompany each application.

Recipients of the Prize may be invited to present a report at a Scientific Meeting of the Old Age Psychiatry Specialist Section.

The Examiners of the Woodford Williams Prize will be the Dean, the Chairman of the Research Committee and two assessors nominated by the Old Age Psychiatry Section. No prize will be awarded if a sufficient standard is not reached.

Entries for the Prize should be submitted to the Dean before 31 March 1988. Proposals should be submitted to the Dean by 31 January 1988 .

*"Members of, or Associates with, the College" means that applications can be received from "registered Members and Fellows of the College" as well as the "registered Affiliates, Honorary Fellows, Corresponding Fellows, Corresponding Associates, Inceptors, New Affiliates and New Associates".

\section{The Peter Scott Memorial Trust Scholarship}

The Peter Scott Memorial Scholarship is awarded from funds subscribed in memory of the late Peter Scott, CBE, and is awarded biennially.

The Scholarship is intended to encourage young doctors or medical students to further their studies in the field of forensic psychiatry or delinquency by enabling them to carry out research, to travel, to write, to complete a research project or to suggest any other relevant activity. The value of the Scholarship is up to $£ 1,000$, and any member of the medical profession, or medical student(s), may apply. More than one Scholarship may be awarded.

Application forms are obtainable from the Education Department at the College and should be completed and returned by 31 March 1988 . The successful candidate(s) will be required to supply a subsequent report and may be asked to present a paper at a meeting of the Royal College of Psychiatrists. 